ern home, at intervals usually of two or three decades, a migrating epidemic influenza begins, moving eastward and westward, with the greater velocity in the latter direction.

Now since the combating of these two epidemic diseases, when they become widely and severely pandemic, is attended with such very great difficulty and is of such dubious success, and this notwithstanding the prodigious public health contests which are waged against them in which the advantages are all in favor of the invading micro-organismal hosts, it would seem as if an effort of central rather than peripheral control might be worth discussion. According to this proposal, an effort at control amounting even to eventual eradication of the diseases in the regions of their endemic survival would be undertaken, an effort, indeed, not occasional and intensively spasmodic, as during the pandemic excursions, but continuous over relatively long periods, in the hope that the seed beds, as it were, of the diseases might be destroyed.

That such an effort at the eradication of a serious epidemic disease may be carried through successfully, the experience with yellow fever abundantly proves. In attacking that disease, the combat was not put off until its epidemic spread had begun and until new territory, such as New Orleans, Jacksonville and Memphis, had been invaded; but the attack was made on its sources at Havana, Panama and now Guayaquil, to which endemic points the extension into new and neutral territory had been traced.

I do not disregard the essential fact, in bringing this suggestion forward, that the control at its sources of yellow fever is quite another and probably far simpler problem than the control in their endemic foci of poliomyelitis and influenza. It is, perhaps, unnecessary to go far into the reasons why the latter would doubtless prove to be far more difficult of accomplishment than has been the former. I am not now engaged in presenting a plan of operation or proposing that the attempt at eradication be made immediately. Our knowledge of all the facts involved in the epidemiology of poliomyelitis, and especially of influenza, may still be too imperfect for immediately effective action. But the very magnitude of the problem of these otherwise uncontrollable epidemic diseases invites to an imaginative outlook which, while perhaps nonrealizable today, may not, in view of the rapidly advancing knowledge of the infectious diseases, be hopelessly out of reach tomorrow.

Nor am I insensible to the labor and cost in money and talent which the setting out on such an ambitious enterprise would entail. But here, at least, is a world problem of such proportions and nature as to invite the participation of all the scientifically advanced countries in a common effort to suppress one of the most menacing enemies of civilized man and of human progress.

In proposing to strive for the high achievement, not merely of parrying the blows struck by destructive epidemics, but of rendering them impotent to strike in the future, we may pause for a moment to reflect on the different ways in which peoples react to great calamities, such as those brought by war and by discase. As the results of a cruel and devastating war, revolutions in governments supposed the most stable may occur; no such result follows on still more devastating epidemics. The recent epidemic of influenza claimed, possibly, more victims than did the great war, and the losses to the world in emotion spent, treasure consumed, and progress impeded are incalculable; yet, through a fortuitous circumstance of psychology, from the one calamity the world may emerge chastened, perhaps even bettered, while from the other, because of a depth of ignorance amounting often even to fatalism, mankind may largely miss the deep meaning of the lesson.

\section{USE OF RADIUM IN FIFTY CASES OF UTERINE HEMORRHAGE}

FROM CAUSES OTHER THAN CARCINOMA OR MYOMAS *

S. M. D. CLARK, M.D.

Professor of Gynecology, Tulane University of Louisiana School of Medicine

NEW ORLEANS

Radium being comparatively a new agent, it is premature to take the position that it has yet reached its maturity or possibilities. As all innovations do, it is now running the critical gamut. In one camp it is unconditionally condemned, while in the other it is equally acclaimed. Where such contention exists the truth is found in the midway position.

Though radium is yet in its developmental period, and though already we have abandoned some of onr earlier fondest hopes, still, in the past five years, there have been deduced certain well established clinical facts.

Menstruation is a complex process influenced by innumerable factors, ranging from undeveloped organs, defective endocrines and new growths down to constitutional dyscrasias. In many instances its derangement is a local expression of a constitutional condition ; therefore it is most difficult correctly to divide cases of uterine bleeding, of these types, into segregated pathologic groups. In some instances the true pathology is not understood. For the purpose of presentation, the cases have been divided into three nominal groups.

GROUP 1. HEMORRHAGE IN YOUNG WOMEN

In Group 1 are placed those cases in which there is an excessive bleeding, with no marked local discomfort, but a decided constitutional impairment resulting from too great a loss of blood. In many of these cases there is no discernible anatomic wrong. Curetting, organotherapy and constitutional remedies fail; the bleeding continues, and in severe cases something radical must be done. What this "something radical" must be reduces itself to the removal of some of the organs, or to allowing the future welfare of the young woman to be jeopardized. Surely many of us have encountered such cases, and the action to take presents a serious problem.

If radium does not act, as we believe, entirely through altering ovarian function, but rather by altering the endometrium and myometrium, then it seems that this is a most valuable field for its use. The literature contains some encouraging reports, and it appears reasonable, as we improve and refine our technic, to expect some substantial help. Certainly it would be most valuable to know that excess bleeding could be controlled and the meristruation not suppressed.

Our experience has not been extensive in this group. In one of five cases there is one in which, by the use of * Read before the Section on Obstetrics, Gynecology and Abdominal
Surgery at the Seventieth Annual Session of the American Medical Surgery at the Seventieth Annual S
Association, Atlantic City, June, 1919. 
small, graded amounts of radium, the flow was returned to normal. In another case, an effort to check the flow by graded doses failed, and the treatment had to be pushed on to complete cessation; but even this was better than an abdominal operation.

\section{ILLUSTRATIVE CASES ${ }^{1}$}

CASE 1 (62447)-History.-Miss R. B., a schoolgirl, aged 17, began menstruation at the age of 12 years. The flow was veiy profuse at the first menstruation and has continued so. She was operated on, June 5, 1917, and a curettage was performed. Since July 17, 1917, she had had practically a continuous vaginal bleeding. Three applications of radium were given, of $1,500 \mathrm{mg}$. hours.

Result.-Complete suppression of the menses followed.

CASi 2 (57958)-History.-A woman, aged 28, had a cyst removed from the right ovary when she was 22 . Four months ago the menstruation began to be excessive and resulted in a flow lasting twenty-five days. She was curetted twice. Four treatments with radium of $3,859 \mathrm{mg}$. hours were given.

Result.-There was complete cessation of menses.

CASE 3 (55149)-History-A woman, aged 33, for several years had had very irregular menstruation, sometimes lasting twenty-eight days. She was operated on for suspension, with no relief. One treatment with radium of $750 \mathrm{mg}$. hours was given.

Result.-The menstruation returned to a normal and two day type.

CASE 4 (57943)-History.-A girl, aged 16, started menstruation at the age of 13 years. It was very scanty and irregular. The uterus was curetted, Sept. 15, 1917, after which the moises stopped for three months, and the patient then bled continuously for two months. A small amount of radium was used from an outside source with no relief. Treatment of $1,275 \mathrm{mg}$. ho.irs was given.

Result.-Two treatments produced a cessation of the menses.

CASE 5 (57783)-History.-Mrs. E. J., aged 25, began menstruation at the age of 14 years, and was made very sick from its inception. The bleeding lasted eight weeks, coming in large clots, and the flow was profuse. The menses were never regular. She had had one living child and two miscarriages, the last one a year ago, followed by four months of bleeding. She had had numerous operations. For the past year she had menstruated twice a month, each period lasting from six to seven days. For the past two months she had had a continuous uterine bleeding. Four applications of radium were given, the first of $75 \mathrm{mg}$., with eleven hours' exposure, and the remaining three of $50 \mathrm{mg}$., with eleven hours' exposure.

Result.-The condition was entirely relieved.

\section{GROUP 2. AGGRAVATED AND INTRACTABLE} DYSMENORRHEA

Cases of violent dysmenorrhea which have resisted all treatment, and in which the general health is markedly impaired, are placed in this group. The affection is most frequently seen in the neurotic type who are reluctantly yielding to advancing years and are as yet unmarried. It is commonly observed in teachers, or in those lately beginning to work, their mission in life still unsettled. The patient has about ten comfortable days in a month, the rest being spent in bed or in struggling to keep up during the premenstrual or the postmenstrual storm. In many of these patients there may be found no anatomic wrong, but the distress is there and is gravely altering her life. We have all had these rebellious cases, in which endocrines, stem pessaries, curetting and climatic changes fail, and in which it is imperative that something be done. As a final measure, if the life is to be useful, menstruation must be stopped.

1. Publication of the cases reported in this paper is made possible through the courtesy of the Radium. Institute of New Orleans. This institute is composed of eight physicians of New Orleans, of whom
the author is one.
We know that radium will cause the cessation, and we know further that the treatment is less painful and upsetting than an ablation operation and, still further, that it does not seem to be followed by as intense nerve disturbances. Twelve such cases are here reported, complete relief being obtained in all, chiefly through suppression; but in one instance the treatment relieved the pain, and normal menstruation continued, just as resulted in Case 3 in the preceding group.

\section{ILLUSTRATIVE CASES}

CASE 6 (64044)-History.-Miss L. S., aged 35, a schoolteacher, began menstruation at the age of 14 years and has always suffered pain, but had gradually grown worse in the past four years. She had been unable to teach in this time during her period. She suffered intense headache and backache, and her general health had been markedly impaired. She scarcely recovered from one month's epoch before another appeared. The organs were normal to palpation. A dilatation and curettage were performed and a stem pessary applied, without relief. She was given three applications of radium of $50 \mathrm{mg}$. and ten hours' exposure each.

Result.-A complete suppression of menstruation and a marked improvement of general health have followed.

CASE 7 (57686)-History.-Mrs. P., aged 28, who began menstruation at the age of 15 years, suffered severe pain and stayed in bed two days each month. She had been married two years, but had no children. She was operated on, March 13,1913 , having the left ovary removed and part of the right. Her general health improved after the operation, but at the menstruation period she suffered severe pain all over the abdomen, and was forced to remain in bed, with frequent urination during the period. Five applications of radium were given, three of $50 \mathrm{mg}$., with ten hours' exposure, and two of $75 \mathrm{mg}$., with ten hours' exposure.

Result.-Suppression of the menstruation followed.

CASE 8 (62803)-History.-Mrs. V. B., aged 23, a saleswoman, began a normal menstruation at the age of 13 , which gave her no trouble until Feb. 14, 1917, when the flow became profuse and very painful. She was curetted in April, 1917. The appendix was removed, May 15, 1917. The flow had been practically continuous since the April operation. The patient suffered great pain in the back, and general discomfort, and was anemic. She was given a treatment of $50 \mathrm{mg}$. of radium, Aug. 26, 1917, for a ten hour period, $50 \mathrm{mg}$., Sept. 9 , 1917, and $25 \mathrm{mg}$., Sept. 19, 1917.

Result.-Complete relief followed.

CASE 9 (65262)-History.-Mrs. P. D., aged 31, who menstruated at the age of 13 years and thereafter regularly and normally, and who had been married fourteen years, having one child, aged 11 years, was operated on four years ago. An appendectomy was performed and a laceration sutured. For the past few years menstruation had been very scant, but the pain was so severe that it necessitated the use of hypodernic injections of morphin. This condition gradually grew worse. Four applications of radium were given, two of $50 \mathrm{mg}$. and two of $75 \mathrm{mg}$., ten hours' exposure each.

Result.-Complete relief followed.

CASE 10 (60654)-History.-Mrs. R. H., aged 33, who began menstruation at the age of 15 years, had been married eleven years, having no pregnancies. She had always suffered excruciating pains at the menstrual period, going to bed three days, and had passed large clots of blood. The flow was very profuse. Five applications of radium were given, each of $50 \mathrm{mg}$. and ten hours' exposure.

Result.-The menstruation was suppressed and there was complete relief.

CASE 11 (57713)-History.-Miss H. H., aged 30, began menstruation at the age of 14 years, and it was regular until she was 17 , when it became irregular and developed pain. The pain had gradually grown more intense and she had to remain in bed one week. The flow was very profuse, especially in the past six months. Six applications of radium were given, each of $50 \mathrm{mg}$. and ten hours' exposure.

Result.-Complete relief followed. 
CAse 12 (53695)-History.-Mrs. P. G., aged 25, who had been married four years, suffered with dysmenorrhea before and after marriage until the birth of her child. The appendix was removed, the ovary resected and the uterus suspended shortly after her confinement. She then suffered with pains in both sides, and with a profuse menstruation, lasting seven days and extremely painful. She also had severe cramps in the legs. Two applications of radium were given, $75 \mathrm{mg}$. total twenty-four mg. hours.

Result.-Complete relief followed.

CASE 13 (61710)-History.-Miss M. A., T. N., aged 35, menstruated normally until ten months ago, when she began suffering great pain and having a profuse flow. She had had a decided loss of weight in the past ten months. Two applications of radium were given, one of $50 \mathrm{mg}$., with ten lours' exposure, and one of $75 \mathrm{mg}$., with ten hours' exposure.

Result.-Suppression of menstruation followed and great improvement.

CASE 14 (68655)-History.-Mrs. V. B., aged 38, had a normal menstruation at the age of 13 years, and had been married fifteen years, having one child, aged 11 , and one miscarriage, seven years ago. Nine months ago an appendectomy and a myomectomy were performed on her. She had a scant menstruation, and felt dreadfully during the period, suffering general prostration. One application of radium of $50 \mathrm{mg}$. was given of $525 \mathrm{mg}$. hours.

Result.-Menstruation stopped for six months and then reappeared as the three day type, with no pain.

CASE 15 (55352)-History.-Mrs. H., aged 35, who had been married ten years, and concerning whom there is no record of menstrual history, was operated on two years ago for profuse menstruation, but without relief. She suffered intense headaches at the time of the flow, necessitating her remaining in bed. Two applications of radium of $75 \mathrm{mg}$. were given, with ten hours' exposure.

Result.-Suppression of menstruation and complete relief.

CASE 16 (56065)-History.-Mrs. E. T, aged 30, had been married eight years and had never suffered from menstrual periods before her marriage. She had been married two years when a child was born, and was healthy for two years after, when pains in the sides and ovaries developed during menstruation. The menstruation began to be irregular and to appear twice a month. The patient was curetted one year ago for continuous bleeding, which was checked temporarily, but again appeared with the former pains. One application of radium of $75 \mathrm{mg}$. was given, with eighteen hours' exposure, a total of $1,350 \mathrm{mg}$. hours.

Result.-The flow gradually decreased. There have been no late reports.

CASE 17 (66803))-History.-Mrs. A. C., aged 32, who had menstruated normally and regularly until two years ago, had been married thirteen years and had had two children, the youngest aged 10. She had had no miscarriages. For the past two years the periods had been exceedingly painful and associated with nausea and intense headaches. Three applications of radium were given, two of $50 \mathrm{mg}$. and one of $75 \mathrm{mg}$., each with ten hours' exposure.

Result.-Complete relief followed.

CASE 18 (71289)-History.-Mrs. M. D., aged 46, who had been married twenty-seven years and had no pregnancies, and whose menstruation was, as a rule, irregular, was operated on five years ago, an appendectomy and the removal of one tube and ovary being performed. After the operation the menses were regular, accompanied by a great deal of pain, requiring her to go to bed for a week. For the past three years she had been menstruating every three weeks; and for the past month the flow was very profuse, lasting from eleven days to two weeks. Four applications of radium of $50 \mathrm{mg}$. were given, with ten hours' exposure.

Result.-Complete suppression of the menses and complete relief followed.

\section{GROUP 3. CHRONIC METRITIS}

In this division falls the greatest number of cases. For want of a better term "chronic metritis" is used. Whether the pathologic condition is polypoid, hyper- trophic or hyperplastic endometritis, or results from myopathic or vascular changes, most of these conditions are combined in the term "chronic metritis."

The ages of the patients are usually between 36 and 56 years. Many have had numbers of children; the uterus is in malposition, enlarged and firmer than normal, having associated therewith an enlarged chronic cervicitis. In these cases, bleeding is often rebellious; the patients may be curetted repeatedly, to no avail, and the final cure comes about through hysterectomy. Often the bleeding is so profuse that packing becomes necessary. To treat the condition, inflammatory diseases must be eliminated first; next, an exploratory curettage is performed in search of malignancy. Then, by the application of radium, the menstrual life is brought to a close. So far as our experience extends, it seems that the nerve upheaval is less through this method than the surgical. It is well known that most of these uteri have about completed the useful period, and when complicated by pathologic changes following a low grade infection, only complete removal gives the desired relief. Radium is unquestionably preferable in that it accomplishes the same result with less discomfort and no danger to life. As will be seen from the histories, thirty-five such cases were treated, with one partial failure. In this case there persisted an occasional bleeding, especially after coitus, and fearing potential malignancy, the uterus was removed.

There is some discomfort associated with radium intra-uterine applications, as seen in malaise, nausea and general lassitude, lasting from twenty-four to thirty-six hours; but this is negligible in most cases, and its worst form is in no way comparable to the operative course. If radium had no other field of virtue than is evidenced in this group, its use is warranted.

Though radium is by no means fully developed, and even if we discount some of the earlier claims for it, there have been produced sufficient positive data to cause it to take rank as a useful agent, and I feel that it should be made available to the localities through cooperating professional groups.

\section{ILLUSTRATIVE CASES}

CASE 19 (58300)-History.-A woman, aged 42, who menstruated at the age of 14 years, and whose flow continued regular and normal, had been married eighteen years. The oldest child was aged 16 and the youngest 11 . For the past year menstruation had been very irregular and very profuse, lasting five days. At the last period there was a heavy flow lasting twelve days. Examination revealed a large uterus, freely movable. Two applications of radium were given, one of $75 \mathrm{mg}$. and the other of $50 \mathrm{mg}$., both with eleven hours' exposure.

Result.-Complete relief followed.

CAse 20 (62969)-History.-Mrs. H. S., aged 29, whose menstruation began when she was 16 , and who has one child, aged 3, was curetted two years ago and had the uterus suspended and the appendix removed. For a year and a half following she had a profuse flow during menstruation, and for the past two months the flow had been almost hemorrhagic, and accompanied with pain and large clots. She had pain in the back and the ovarian region, and lost weight and became constipated and anemic. Three applications of racium were given, each of $50 \mathrm{mg}$, with eleven hours' exposure.

Result.-Complete relief followed.

CASE 21 (61200)-History.-Mrs. L. T., aged 35, began menstruation at the age of 15 years, which was irregular and lasted eight days from the start. She had been married three months. The appendix was removed in September, 1916. Since the operation she had been bleeding twice a monih. Menstruation was profuse and lasted from ten days to two 
weeks. She was very weak from the loss of blood. Two applications of radium of $50 \mathrm{mg}$. each were given, with eleven hours' exposure.

Result.-Complete suppression of the menses followed.

CASE 22 (65485)-History.-Mrs. F. Y., aged 36, who had been married ten years and had one child, aged 9 (no miscarriages), had menstruation which was regular, but always painful. About a year ago the flow became more profuse and more' painful. She was operated on in June, 1917, an appendectomy, a removal of the left ovary and a resection of the right ovary being performed. Six weeks after the operation she had a severe hemorrhage, necessitating packing. The uterus was large, freely movable and normal in position. The patient was a marked neurotic and definitely anemic, and was almost a physical wreck from the excessive bleeding. Four applications of radium were given, two of $75 \mathrm{mg}$. and two of $50 \mathrm{mg}$. each, with ten hours' exposure.

Result.-A complete suppression of menstruation and a complete transformation constitutionally followed.

CASE 23 (64525)-History.-Mrs. A. P., aged 40, had been bleeding profusely off and on for the preceding nine years, and an amputation of the cervix and a curettage were performed five years ago. She has seven children, the youngest aged 10. After the operation, the bleeding was more profuse, hemorrhagic at times. There were severe pains in the abdomen during menstruation. Four applications of radium of $50 \mathrm{mg}$. each were given, with ten hours' exposure.

Result.-Complete relief followed.

CASE 24 (73309)-History.-Mrs. W. R., aged 31, had had a profuse uterine bleeding for three weeks. She was curetted, Sept. 16, 1918. Relief followed for only two months, and then bleeding recurred. There was a slightly bloody discharge off and on, and the flow was very profuse at the time of her period. Three applications of radium of $50 \mathrm{mg}$. each were given, with ten hours' exposure.

Result.-Complete relief followed.

CASE 25 (56058)-History.-The patient, aged 38, began menstruation at the age of 14 years. The flow was regular but profuse. She had two children. For several years shè had had frequent bleeding, both at the regular period and between the periods. Curettage relieved her for only two months. The bleeding stopped for ten days; then, September 13 , the flow started and continued almost hemorrhagic, until November 9 . One application of $75 \mathrm{mg}$. of radium was given, with twelve hours' exposure, $900 \mathrm{mg}$. hours.

Result.-There has been an improvement in bleeding, but it has not entirely stopped.

CASE 26 (61691)-History.-Mrs. A. J., aged 31, was perfectly healthy until four years ago, when her menstruation began to be irregular, very profuse, and to last five days. She was operated on one year ago. A dilatation and curettage and an appendectomy were performed, but no relief was obtained. The patient suffered loss in weight and became anemic. Four applications of radium were given, three of $50 \mathrm{mg}$. and one of $75 \mathrm{mg}$. each, with eleven hours' exposure.

Result.-The condition was relieved.

CASE 27 (65465)-History.-A woman, aged 42, began menstruation at the age of 17 years, which was regular and of five days' duration, and had had five full time children, the youngest of whom is aged 5 . The patient was well until May 11, 1917, when she was awakened by a flooding which lasted ten hours. She had not flooded any more until two months ago. During the past two months she had had two hemorrhages, gradually growing worse. During this hemorrhage her temperature was as high as 103.5. Feb. 22, 1918, a dilatation and curettage was performed. Seventy-five mg. of radium were introduced at the time of operation, with nineteen hours' exposure, 1,425 mg. hours. March 13, $75 \mathrm{mg}$. were given, $900 \mathrm{mg}$. hours. The patient returned to the city a few months ago with a temperature of 102 , whereupon a pyometra was discovered containing from 6 to 8 ounces of pus, which was drained.

Result.-The patient continued normal.

CASE 28 (73517)-History.-Mrs. O. W., aged 39, concerning whom there was nothing of interest in her early menstrual life, was curetted three times for excessive bleeding, the last curettage being performed eleven years ago. She has one full term child, aged 16 , and had one miscarriage eight years ago. Since this time had had excessive bleeding. The flow had continued for five or six months and been very profuse at times. Three applications of radium were given, two of $50 \mathrm{mg}$. and 1 of $75 \mathrm{mg}$.

Result.-Complete cessation of the menses followed.

CASE 29 (56976)-History.-Mrs. M. C., aged 36, had had menorrhagia for the past four years. Three months ago she had a severe hemorrhage, and there had been an excessive flow for the past two months. One application of radium of $75 \mathrm{mg}$. was given, with twenty-four hours' exposure; four days later another, with twenty-two hours' exposure, and another with fifteen hours' exposure.

Result.-Complete cessation of the menses has followed.

CASE 30 (67828)-History.-Mrs. C. O., aged 40, who had had two children, the youngest of whom is aged 16, menstruated regularly until one year ago; she then began having flooding spells lasting from five to six days, and loss in weight. One application of $50 \mathrm{mg}$. of radium was given, with ten hours' exposure:

Result.-No return of bleeding; she was discharged relieved.

CASE 31 (73559)-History.-Mrs. S. C., aged 32, who had had four children, of whom the youngest is aged 4, had always had profuse bleeding during menstruation, but in the past four years it had increased in duration and in quantity. The patient was operated on a year ago; a cyst on the ovary was removed and a curettage performed. Since that time the bleeding has been more profuse and alarming, so that packing was the only means of control. She came to her physician to know if the uterus should be removed or if there was any other way that the alarming hemorrhage could be controlled. Three applications of radium were given, two of $75 \mathrm{mg}$. (one with ten hours' exposure and the other with twenty-four hours' exposure), and one of $50 \mathrm{mg}$, with ten hours' exposure

Result.-Suppression of the menses and marked improvement constitutionally followed.

CASE 32 (57201)-History.-The patient, whose menstruation began when she was 15 , and which was always regular until two years ago, had had five children, three of whom are living. Four years before the radium was applied, an amputation of the cervix and a curettage were performed for excessive bleeding and irregular menstruation. At the time of the operation the uterus was large and freely movable, and the amputation was performed with the hope that the uterus would diminish in size. The patient objected to removal of the uterus. Three applications of radium were given, of 100,75 and $50 \mathrm{mg}$., with ten hours' exposure each.

Result.-The flow became slight, with spots after coitus. A hysterectomy was performed, but no malignancy found.

CASE 33 (56497) - -History.-Mrs. P., aged 46, was in good health until six years ago, when she began to suffer with painful menstruation. Three years ago she began having an irregular flow, showing every three weeks and rather profuse. She was operated on one and one-half years ago for the removal of a polypus on the cervix. She also took roentgenray treatments. The flow reappeared six months later, hemorrhagic in character. One application of $75 \mathrm{mg}$. of radium was given, with ten hours' exposure.

Result-Painful menstruation was entirely stopped and there has been no vaginal discharge.

CASE 34 (62617)-History.-Mrs. A. D., of whose case there is an incomplete history, was curetted unsuccessfully for excessive menstruation and profuse vaginal discharge. She was given an application of $25 \mathrm{mg}$. of radium, with twelve hours' exposure, with two large exposures.

Result.-Complete cessation of the menses followed.

CASE 35 (60940)-History.-Mrs. E. D., aged 41, whose menstruation began when she was aged 14 , and was of the regular normal type, had been married nineteen years and had had two children, the oldest of whom was aged 16 and the youngest 11. She had had almost continuous utcrine bleeding for the past year, very profuse at times and passing large clots. Amputation of the cervix was performed, June 
30, 1917. Two applications of $50 \mathrm{mg}$. of radium, each with ten hours' exposure, were given.

Result.-Complete relief followed.

CASE 36 (65653)-History.-A woman, aged 42, who had been married twenty-one years, and has one child, aged 17, had been operated on six times for the repair of laceration and the removal of one ovary and tube. She had had fairly good health, only painful menstruation. Three months ago the menstruation began being irregular, appearing every fifteen days and lasting nine days. For the last six weeks she had been bleeding practically continuously, passing large clots. Three applications of $50 \mathrm{mg}$. of radium were given, each with ten hours' exposure.

Result-Cessation of menses and complete relief followed.

CASE 37 (68847) - History.-Miss H. K., aged 40, the history of whose case is incomplete, had profuse vaginal bleeding. There had been previous local treatment without result. Three applications of $50 \mathrm{mg}$. of radium were given, each with ten hours' exposure.

Result.-Complete cessation of the menses followed.

CASE 38 (63434)-History.-Mrs. M. L., aged 51, who had had. ten children, of whom the youngest is aged 8 , was curetted eight years ago for bleeding almost continuously, with a profuse flow. The menstruation was regular until twelve years ago, and since that time the patient had been bleeding in between the periods, the flow lasting from four to five days. Preceding the radium treatment, the bleeding was profuse and hemorrhagic in character. The vagina had to be packed to stop the flow. Two applications of radium were given, one of $50 \mathrm{mg}$., with eleven and one-half hours' exposure, and one of $75 \mathrm{mg}$., with eleven hours' exposure.

Result.-Complete cessation of the menses followed.

CASE 39 (69957)-History.-Mrs. E. A., aged 50, who had had six children, of whom the youngest is aged 14, had had no menstrual disturbance until four months ago, and since that time had been bleeding almost continuously with a profuse flow, at times hemorrhagic in character. She was quite anemic, and felt weak from the loss of blood. Two applications of radium were given, one of $75 \mathrm{mg}$., and one of $50 \mathrm{mg}$., each with ten hours' exposure.

Result.-Complete cessation of the menses followed.

CASE 40 (71949) - History.-Mrs. C. P., aged 53, who went through the menopatuse four years ago, a year later, from excitement and nervousness, had bleeding start again. There had been a slight flow, lasting one or two days, for the last year. Malignancy was eliminated. Two applications of 50 mg. of radium were given, each with ten hours' exposure.

Result.-There was no evidence of bleeding.

CASE 41 (54998)-History.-A schoolteacher, aged 42, who began menstruation at the age of 14 years and was anemic, had no abnormal features of the flow until six years ago. when she developed an irregularity and menorrhagia. The condition had gradually grown worse, and she had been bleeding for the last ninety-five days. The uterus was slightly enlarged, the adnexae negative. Two applications of $50 \mathrm{mg}$. of radium were given, each for twelve hours, and two of 75 mg. for eleven hours.

Result.-Complete cessation of the menses, with a marked improvement of general health followed.

CASE 42 (53650)-History.-Mrs. M. L., aged 40, a healthy, normal person, had no menstrual disturbance until one year before the radium treatment, when the flow began to increase in duration and quantity, and a flooding spell occurred in May, 1916. When the patient was examined, June 1, 1916, she had a profuse, bloody, vaginal discharge. The uterus was about the size of a double fist, symmetrical and freely movable. There was no adnexa trouble. Fifty $\mathrm{mg}$. of radium were applied, June 5, with eleven and one-half hours' exposure, and $75 \mathrm{mg}$., June 20 , with eleven hours' exposure.

Result.-The uterus is now normal, and a complete cessation of the menses has followed.

CASE 43 (65626)-History.-Mrs. M. G., aged 40, who had been married twenty years and had three children, was operated on for complete laceration. For the past year the menstruation had been irregular and profuse in quantity, and there had been continuous bleeding for the past eight months. The patient was anemic and very nervous, and had lost in weight. Three applications of radium were given, one of 75 $\mathrm{mg}$. for eleven, and two of $50 \mathrm{mg}$. for ten and one-half hours.

Result.-There has been a suppression of the menses. Marked menopause symptoms were treated with hypodermic injections of corpus luteum.

CASE 44 (65596)-History.-Mrs. K. K., aged 42, who had been married seventeen years, and had had four children; all living, the youngest of whom is aged 8 , had been curetted twice, the last time two years ago. The flow temporarily improved after curettage, but reappeared, quite profuse. For the past few months, the patient had been bleeding continuously, passing large clots. Three applications of radium, each of $50 \mathrm{gm}$., with eleven hours' exposure, were given. Result.-The condition was completely relieved.

CASE 45 (70021)-History.-Mrs. B. L., the history of whose case is incomplete, began to have irregular menstruation ten years ago. For the past three or four months she had had flooding spells. She was curetted two years ago and operated on twice since then, but the flow continued. Two applications of radium were given, each of $50 \mathrm{mg}$., and ten hours' exposure.

Result.-The condition was completely relieved.

CASE 46 (61565)-History.-Mrs. J. M., aged 39, who had had her last child four years ago, was well until two years ago, when she began bleeding excessively. Curettage gave temporary relief. For the past month she had had a continuous flow. She had lost in weight and was anemic. Six applications of radium were given: Aug. 8, 1917, $50 \mathrm{mg}$, twelve hours' exposure; August 15, $75 \mathrm{mg}$., twelve hours' exposure; September 3, 25 mg., eleven hours' exposure; November 27, $50 \mathrm{mg}$., eleven hours' exposure; Jan. 1, 1918, $50 \mathrm{mg}$., ten hours' exposure, and June 6,50 mg., tèn hours exposure.

\section{Result.-Complete relief followed.}

CASE 47 (53807)-History--Mrs. B. V. M., aged 38, of whose case there is an incomplete history, had a miscarriage four years ago. One month later excessive bleeding started, lasting four days. Every month she bled excessively, suffering with pains in the right side, the back and lower extremities. Three applications of radium were given, two of $50 \mathrm{mg}$. and one of $75 \mathrm{mg}$., each with eleven hours' exposure.

Result.-The excessive flow was controlled and the patient now menstruates normally, the menstruation lasting six days.

CASE 48 (58277)-History.-A woman, aged 30, suffered from profuse and prolonged menstruation. An appendectomy was performed and a cystic ovary and small polypus removed, Dec. 16, 1916. A practically continuous hemorrhage had persisted since the operation. Four treatments with radium, totaling $2,550 \mathrm{mg}$. hours, were given.

Result.-Suppression of the menses followed.

CASE 49 (56051)-History.-The patient, aged 45, had always had profuse menstruation, lasting for five or six days. The last few years she had menstruated twice in a month. The flow was copious. The patient had been treated locally for a long period. Two treatments with radium, totaling $2,675 \mathrm{mg}$. hours, were given.

Result.-The condition was completely relieved.

CASE 50 (56753)-History.-A. woman, aged 35 years, had had flooding spells for several years, lasting five or six days. Blood appeared in large clots, and just previous to the radium treatment there was almost a continuous bloody discharge. The patient had been curetted twice, and her appendix had been removed. She had had two courses of deep, roentgenray therapy, which checked the flow for a year, but it reappeared in hemorrhage form. One treatment with radium, of $550 \mathrm{mg}$. hours, was given.

Result.-Complete stoppage of menstruation followed.

CASE 51 (55804)-History-A woman, aged 44, had been menstruating irregularly for the past year and a half. The flow was very profuse and returned every nineteen days, accompanied by pains in the back. One treatment with radium, of $865 \mathrm{mg}$. hours, was given.

Result.-Complete relief followed. 